Working papers series

\author{
WP ECON 17.05
}

\title{
Faster estimation of discrete time duration models with unobserved heterogeneity using hshaz2
}

\author{
David Troncoso-Ponce
}

Department of Economics, Universidad Pablo de Olavide

Keywords: Duration analysis, Unobserved heterogeneity, d2 $\mathrm{ml}$ method, hshaz, hshaz2, Hessian matrix, Stata

JEL Classification: C41, J64 


\title{
Faster estimation of discrete time duration models with unobserved heterogeneity using hshaz 2
}

\author{
David Troncoso Ponce \\ Pablo de Olavide University \\ Seville, Spain \\ Email: dtropon@upo.es
}

\begin{abstract}
This article presents hshaz2, a new Stata command that uses $\mathrm{d} 2 \mathrm{ml}$ method to estimate discrete time duration models with unobserved heterogeneity. The main advantage of using hshaz2 is the gain in computation speed, that takes special relevance as the sample size increases. Estimation results show that, on a sample size of 568,042 observations, hshaz2 spends 0.42 and 1.13 minutes to achieve the convergence of a discrete time proportional hazard model with two and three points of support, respectively. Furthermore, hshaz2 allows for the estimation of multispell duration models, where individuals may be observed at risk of exiting more than once. Using, a sample with 1,547,507 observations, hshaz2 spends 1.17 and 2.17 minutes to achieve convergence of a multispell discrete time proportional hazard model with two and three points of support, respectively.
\end{abstract}

Keywords: Duration analysis, Unobserved heterogeneity, d2 ml method, hshaz, hshaz2, Hessian matrix

\section{Acknowledgement}

I am greatful to professor Stephen Jenkins for his helpful comments and suggestions that have contributed to significantly improve this work, and for allowing me to use Stata code of his hshaz's command syntax and helpfile. I also thank financial support of research project SEJ-6882 from Junta de Andalucía. This article has been finished during a postdoctoral research stay at Fundación de Estudios de Economía Aplicada (FEDEA).

\section{Introduction}

Time required to estimate discrete time duration models that account for the presence of unobserved heterogeneity (hereafter, UH) uses to be an important concern for applied researchers when have to deal with large datasets. ${ }^{1}$ Stata command hshaz, written by professor Stephen Jenkins, estimates proportional discrete time duration models taking into account the the presence of $\mathrm{UH}$, following to [Heckman and Singer, 1984]. hshaz uses do ml method to achieve

\footnotetext{
${ }^{1}$ For the purpose of this article, I consider a large dataset as those with at least one million observations, as for example, longitudinal data that comes from Social Security administrative records.
} 
convergence of the log-likelihood function, which computes numerical approximation to first and second order derivatives, that composes gradient vector and Hessian matrix, respectively.

This article presents hshaz2, a new Stata command that provides the algebraic expressions of both first and second order partial derivatives of the loglikelihood function estimated by hshaz command, and describes its main characteristics. Thus, hshaz2 also estimates, using maximum likelihood method, discrete time proportional hazard rate models with UH. However, hshaz and hshaz2 differ in the Stata ml method used to achieve convergence of the loglikelihood: hshaz uses d0 ml method, whereas hshaz2 uses d2 ml method.

The main advantage of programming the algebraic expressions of first and, above all, second order derivatives of the log-likelihood function are twofold: First, higher reliability on the standard errors of parameters estimates. Second, and the most important issue, the gains obtained in computation speed to achieve the model convergence using d2 method [Gould et al., 2010]. ${ }^{2}$

The rest of the article estructures as follows: Section 2 describes the database used to obtain estimation results; the econometric model and hshaz2 command syntax are explained in Sections 3 and 4, respectively; Section 5 presents estimation results, and Section 6 describes some details on the reparameterization of mass-points probability parameters. Finally, Section 7 concludes.

\section{Database: The Continuous Sample of Working Histories}

I analyze a longitudinal sample composed of 44,077 unemployed workers, aged 16-37 year-old, in the Spanish labor market for the period 2000-2013, that comes from the Continuous Sample of Working Histories database (CSWH, hereafter). The CSWH is a longitudinal database that provides the working histories records of more than one million people, who represent a $4 \%$ non-stratified random draw from a target population, composed of any person with a contribution relation with the Spanish Social Security Administration. It includes both wage workers and recipients of Social Security benefits, namely, unemployment benefits, disability, survivor pension and maternity leave. ${ }^{3}$

The CSWH contains detailed information on each employment and unemployment episodes experienced by workers through their entire working histories. The information provided by the CSWH can be grouped into several categories: First, personal characteristics of workers (gender, age, nationality, educational

\footnotetext{
${ }^{2} \mathrm{~A}$ detailed explanation, using an applied approach, on the estimation of duration models using hshaz command is available at the following link: http://www.iser.essex.ac.uk/teaching/stephenj/ec968/index.php

3 [García-Pérez, 2008] and [Lapuerta, 2010] contain a deep exposition about features of CSWH as well as all necessary techniques to perform a duration analysis using working lives information.
} 
level, residence place, etc); Second, job characteristics (type of labor contract, part-time coefficient, qualification level, etc); Third, information on the employer (firm size, activity sector, etc). Furthermore, an important feature of the $\mathrm{CSWH}$ is that provides the beginning and termination dates of all employment and unemployment episodes, which takes special interest for duration analysis.

For the unispell duration model estimation, that will be explained in Subsection 5.1, each unemployment episode has been expanded in monthly intervals. Thus, each unemployed worker is observed (and, therefore, contributes to the likelihood function) as many times as the number of months the unemployment episode lasts. After the database has been expanded, the sample size increases up to 568,042 observations. Moreover, the duration variables as well as all explanatory variables that vary with unemployment duration (such as, age, squared age, etc) have been generated in order to correctly measure timevarying covariates.

\section{Econometric model}

This Section briefly describes the main features of the econometric models that will be estimate in Section 5. The main goal of this kind of models is to analyze duration spent by a population in a specific state (in this example, unemployment state), as well as to analyze the set of factors, observable and above all unobservable, that affect time spent in that state.

Let's consider an individual beginning an unemployment episode at time $T=1$ (time $T$ is measured in month intervals). The unemployed worker is observed monthly during the unemployment episode until either he/she finds a new job, or the observation window ends. Unemployment duration is analyzed by estimating the hazard rate out of unemployment at each observed month.

The hazard rate out of unemployment estimated by hshaz2 (and hshaz) takes the following functional form:

$$
h(t \mid x, \eta)=1-\exp (-\exp (\lambda(t)+x \beta+\eta))
$$

As the expression above shows, the hazard rate at month $T=t$ depends on time (months) spent in the current unemployment state (i.e. duration dependence), captured by $\lambda(t)$, as well as on a set of covariates summarized by $x$ vector. ${ }^{4}$ Furthermore, the hazard rate also depends on an unobserved component given by $\eta$, that mesasures factors, such as job search effort, motivation, ability, etc, that are unobserved to the researcher and may affect the transition rate out of unemployment.

To estimate the unobserved heterogeneity distribution, following [Heckman and Singer, 1984], it is assumed the existence of different types of unemployed workers who differ between them in unobserved characteristics (such as, as mentioned above,

\footnotetext{
${ }^{4} x$ vector may contain both time-fixed and time-varying covariates.
} 
motivation, ability, etc), that affect the transition rate out of unemployment. Therefore, the whole population is composed of a discrete mixture distribution of all the types of unemployed workers considered by the econometric model. The presence of each type of unemployed workers in the whole population is weighted by the probability of observing it, that is estimated jointly with the rest of the model parameters.

The contribution to the likelihood function of an individual $i$ is given by the following expression:

$$
L_{i}=\sum_{j=1}^{P} \pi_{j}\left\{\prod_{t=1}^{T_{i}} \frac{h\left(T=t \mid \lambda(t), x_{i t}, \eta_{j}\right)^{y_{i t}}}{\left(1-h\left(T=t \mid \lambda(t), x_{i t}, \eta_{j}\right)\right)^{\left(1-y_{i t}\right)}} S\left(T=t \mid \lambda(t), x_{i t}, \eta_{j}\right)^{\left(1-y_{i t}\right)}\right\}
$$

Where $h\left(T=t \mid \lambda(t), x_{i t}, \eta_{j}\right)$ and $S\left(T=t \mid \lambda(t), x_{i t}, \eta_{j}\right)$ denote the hazard rate and the survival function ${ }^{5}$ observed at month $T=t$, respectively, conditional on the duration dependence $\lambda(t)$, on the set of covariates $x_{i t}$, and on belonging to the type of unemployed workers with unobserved characteristics given by $\eta_{j} .{ }^{6}$

The discrete probability distribution of unobserved heterogeneity is given by the estimation of the vector $\left(\pi_{1}, \pi_{2}, \ldots, \pi_{P}\right)$, with $\pi_{1}=1-\sum_{l=2}^{P} \pi_{l}$ and $\pi_{j}=\frac{e^{p_{j}}}{1+\sum_{l=2}^{P} e^{p_{l}}}, j=2,3, \ldots, P$. Each $\pi_{j}$ parameter estimates the probability of observing each type of workers in the whole population.

Dependent variable $y_{i t}=\{0,1\}$ denotes a dummy variable that takes value 1 if worker $i$ exits out of unemployment at month $T=t$, and takes value zero otherwise. $^{7}$

Finally, the total likelihood function is given by:

$L=\sum_{i=1}^{N} \sum_{j=1}^{P} \pi_{j}\left\{\prod_{t=1}^{T_{i}} \frac{h\left(T=t \mid \lambda(t), x_{i t}, \eta_{j}\right)^{y_{i t}}}{\left(1-h\left(T=t \mid \lambda(t), x_{i t}, \eta_{j}\right)\right)^{\left(1-y_{i t}\right)}} S\left(T=t \mid \lambda(t), x_{i t}, \eta_{j}\right)^{\left(1-y_{i t}\right)}\right\}$

hshaz command maximizes, using d0 $\mathrm{ml}$ method, the natural logarithm of $L$ to estimate model parameters. The main contribution of hshaz2 command is that it provides the algrebraic expressions of both first and second order derivatives of the natural logarithm of $L$, and therefore, achieves the convergence using d2 ml method.

\section{Command syntax}

As has been explained in Section 1, the main contribution of hshaz2 command is the programming of both first and second order derivatives to achieve faster

\footnotetext{
${ }^{5} S\left(T=t \mid \lambda(t), x_{i t}, \eta_{j}\right)=\left(\left(1-h\left(T=1 \mid \lambda(1), x_{i 1}, \eta_{j}\right)\right)\right)\left(\left(1-h\left(T=2 \mid \lambda(2), x_{i 2}, \eta_{j}\right)\right)\right) \ldots((1-$ $\left.\left.h\left(T=t-1 \mid \lambda(t-1), x_{i t-1}, \eta_{j}\right)\right)\right)\left(\left(1-h\left(T=t \mid \lambda(t), x_{i t}, \eta_{j}\right)\right)\right)$

${ }^{6}$ It is assumed that unobserved characteristics do not vary with time and are not correlated to the rest of explanatory variables included in the specification of the hazard rate.

${ }^{7}$ Dependent variable $y_{i t}$ refers to dead(deadvar) of hshaz2 command.
} 
estimations by using $\mathrm{d} 2 \mathrm{ml}$ method. The programming of gradient vector and Hessian matrix do not affect the estimation output reported by the former hshaz command, in the sense that the set of parameters to be estimated is the same, either by using d0 or d2 $\mathrm{ml}$ methods. Therefore, the command syntax of hshaz2 shares the same estructure that hshaz's, and also makes use of the same terminology to refer to the estimation output.

This section describes the main estructure of hshaz2 command syntax and explains the options allowed by hshaz2 for the estimation process.

The hshaz2 command syntax is:

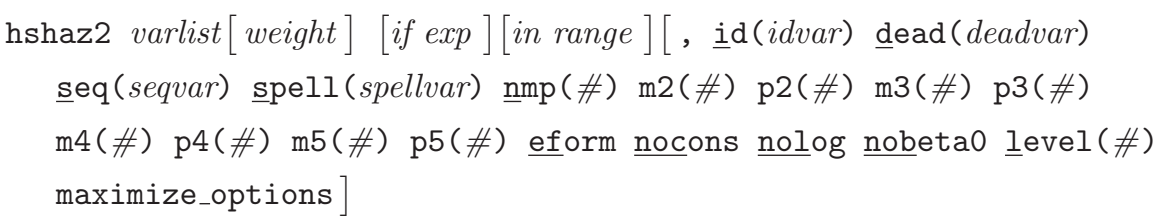

As can be seen, the only element added by hshaz2 to the (hshaz's) command syntax is an option(.), called spell(spellvar). The hshaz2 command allows for the estimation of multiple spells duration models, by which individuals may be observed at risk of exiting more than once. In such cases, it is necessary to correctly identify and to sort the different episodes experienced by each person in the estimation sample. This is the goal of the option spell(spellvar), where spellvar must be a numeric variable that identifies the sequential order of the spells experienced by each individual in the sample. This will be explained in detail in Subsection 5.2.

\section{Estimation}

This Section presents results of fitting discrete time duration models on the sample of unemployed workers described in Section 2. The aim of this Section is to show time saving involved by using hshaz2 command in comparison with hshaz, highlighting the importance of using $\mathrm{d} 2 \mathrm{ml}$ method to achieve convergence. In 5.1 , I use both hshaz2 and hshaz commands to estimate two unispell duration models, with two and three mass-points, respectively. Once the results are obtained, the estimation speed of hshaz2 and hshaz commands are compared. Finally, in Subsection 5.2, I use hshaz2 command to estimate two multispell duration models, with two and three points of support for the identification of the unobserved heterogeneity, respectively. ${ }^{8}$

\subsection{Fitting unispell duration models using hshaz and hshaz2}

Pages 7 and 8 present the estimation output of fitting a duration model with two mass-points, running hshaz2 and hshaz commands, respectively. The rest

\footnotetext{
${ }^{8} \mathrm{I}$ work with Stata $14.0 \mathrm{MP}$ - Parallel edition 64 bits. The machine employed to obtain estimation results incorporates an Intel(R) Core(TM) i7-6700HQ CPU at $2.60 \mathrm{GHz}$, and 12 Gb RAM memory. The operating system is Windows 10 Home, and Stata $14 \mathrm{MP}$ version.
} 
of tables with detailed estimation results are shown at final Appendix. Comments on coeficients estimates will only focus mainly on the different duration dependence effect shown by estimation output with and without controlling for the presence of unobserved heterogeneity. The interpretacion of the rest of estimated coefficients are not commented, because of the main purpose of these regressions is to highlight that hshaz2 command replicates the results obtained by hshaz command, and therefore, it is not intended to address a regression analysis to properly estimate the effect of a set of covariates on the probability of exiting out of unemployment.

The set of covariates is included in the specification of the hazard rate for control purposes, and summarizes: 1) personal characteristics of the unemployed workers, such as, gender, age and squared age, ${ }^{9}$ nationality, ${ }^{10}$ and educational level; 2) characteristics of the current unemployment spell, such as, a dummy variable to identify whether the unemployed worker receives unemployment benefits, as well as an interaction between this dummy variable and the natural logarithm of the duration of current unemployment spell; 3) the quarterly unemployment rate to capture bussiness cycle effects on the transition rate out of unemployment; 4) a set of dummy variables that identify the Spanish regions to capture regional effects. Additionally to the duration dependence specification (using a two order polinomial of the natural logarithm of the duration of current unemployment spell), three dummy variables are included to identify months 12, 18 and 24. These dummy variables are included to capture exit peaks, frequently observed in unemployment duration analysis, that may be due to unemployment benefits exhaustion effects.

Coefficient estimates of model with UH show positive duration dependence $(\log (t)=3.614)$, but this positive effect decreases $\left(\log (t)^{2}=-0.949\right)$ as time spent in current unemployment state increases. Moreover, comparison between coefficient estimates with and without UH reveals the importance of controlling for the presence of UH. Thus, coefficient estimates of two mass-point duration model that does not control the presence of UH underestimates $(\log (t)=1.43$ and $\left.\log (t)^{2}=-0.554\right)$ the effect of unemployment duration dependence.

Regarding the estimation of the unobserved heterogeneity distribution, $71.6 \%$ of the sample are Type I unemployed workers, and the rest $28.4 \%$ belongs to Type II group. For the correct interpretation of UH coefficients, it is necessary to take into account that, as $\eta_{1}$ is set to zero, then $\eta_{2}$ estimates the differential unobserved effect (of being Type II unemployed workers) on the probability of exiting out of unemployment state, with respect to estimated coefficient of the regression constant term, -5.159 . Therefore, the estimated unobserved effect of being Type I and Type II unemployed workers are given by -5.159 and -6.085 $(=-5.159-0.926)$, respectively.

\footnotetext{
${ }^{9}$ Age covariates measure the difference between the current age (time-varying age) with respect to the legal working age in the Spanish labor market, 16 years-old.

${ }^{10}$ Nationality effect is captured using a dummy variable, that takes value one if the unemployed worker is not Spanish, to identify whether the unemployed worker is not Spanish.
} 
. display "Started at \$S_TIME"

Started at 19:19:53

- hshaz2 'varsaleU', id(codind) seq(j) d(exit) nmp(2) difficult

(output omitted)

Discrete time PH model, with discrete mixture Number of obs

Log likelihood $=-122078.61$

LR $\operatorname{chi2()}$

Prob > chi2

\begin{tabular}{|c|c|c|c|c|c|c|}
\hline exit & Coef. & Std. Err. & $z$ & $\mathrm{P}>|z|$ & {$[95 \%$ Conf. } & Interval] \\
\hline \multicolumn{7}{|l|}{ hazard } \\
\hline Injunemp & 3.614478 & .0420878 & 85.88 & 0.000 & 3.531987 & 3.696968 \\
\hline Injunemp2 & -.9491475 & .0099174 & -95.71 & 0.000 & -.9685853 & -.9297097 \\
\hline month12 & .1622685 & .0306302 & 5.30 & 0.000 & .1022344 & .2223027 \\
\hline month18 & .1378142 & .051428 & 2.68 & 0.007 & .0370172 & .2386111 \\
\hline month24 & .7349469 & .0620328 & 11.85 & 0.000 & .6133649 & .8565289 \\
\hline $\mathrm{ub}$ & -1.28535 & .0850207 & -15.12 & 0.000 & -1.451988 & -1.118713 \\
\hline ubxlnjunemp & .5991264 & .04521 & 13.25 & 0.000 & .5105164 & .6877363 \\
\hline female & -.2608072 & .0143061 & -18.23 & 0.000 & -.2888466 & -.2327679 \\
\hline age16tv & .1813952 & .0079179 & 22.91 & 0.000 & .1658763 & .196914 \\
\hline age16tv2 & -.0133666 & .0007284 & -18.35 & 0.000 & -.0147943 & -.011939 \\
\hline educcompul1 & .090299 & .0193612 & 4.66 & 0.000 & .0523517 & .1282463 \\
\hline educcompul2 & .2061935 & .0143468 & 14.37 & 0.000 & .1780742 & .2343127 \\
\hline inmigra & .1978054 & .0221707 & 8.92 & 0.000 & .1543517 & .2412591 \\
\hline unrate & -.0783014 & .0017806 & -43.98 & 0.000 & -.0817913 & -.0748116 \\
\hline andal & .3975539 & .0242093 & 16.42 & 0.000 & .3501046 & .4450033 \\
\hline aragon & -.3055231 & .0429434 & -7.11 & 0.000 & -.3896905 & -.2213556 \\
\hline astur & -.1925411 & .0484716 & -3.97 & 0.000 & -.2875437 & -.0975386 \\
\hline balear & .104185 & .0369932 & 2.82 & 0.005 & .0316797 & .1766903 \\
\hline canar & .1056043 & .0322674 & 3.27 & 0.001 & .0423613 & .1688473 \\
\hline cantab & -.1365828 & .0591541 & -2.31 & 0.021 & -.2525228 & -.0206428 \\
\hline castman & -.0313442 & .0308195 & -1.02 & 0.309 & -.0917493 & .029061 \\
\hline castleon & -.0867659 & .0323628 & -2.68 & 0.007 & -.1501957 & -.023336 \\
\hline valenc & .0931641 & .0235731 & 3.95 & 0.000 & .0469617 & .1393665 \\
\hline extrem & .2210893 & .0479023 & 4.62 & 0.000 & .1272026 & .3149761 \\
\hline galic & -.1072949 & .0294785 & -3.64 & 0.000 & -.1650717 & -.0495181 \\
\hline murcia & .0607897 & .0389267 & 1.56 & 0.118 & -.0155053 & .1370846 \\
\hline navarr & -.3874108 & .0714269 & -5.42 & 0.000 & -.5274051 & -.2474166 \\
\hline vasco & -.2923917 & .0420199 & -6.96 & 0.000 & -.3747493 & -.2100341 \\
\hline rioja & -.1261293 & .0740175 & -1.70 & 0.088 & -.2712009 & .0189422 \\
\hline _cons & -5.159466 & .0520456 & -99.13 & 0.000 & -5.261473 & -5.057458 \\
\hline \multicolumn{7}{|l|}{$\mathrm{m} 2$} \\
\hline _cons & 3.532398 & .0322314 & 109.59 & 0.000 & 3.469226 & 3.59557 \\
\hline \multicolumn{7}{|l|}{ logitp2 } \\
\hline _ cons & -.9266265 & .0159517 & -58.09 & 0.000 & -.9578912 & -.8953618 \\
\hline Prob. Type 1 & .7163904 & .003241 & 221.04 & 0.000 & .7099954 & .7226994 \\
\hline Prob. Type 2 & .2836096 & .003241 & 87.51 & 0.000 & .2773006 & .2900046 \\
\hline
\end{tabular}

Note: $\mathrm{m} 1=0$

. display "Finished at \$S_TIME"

Finished at 19:20:35 
. display "Started at \$S_TIME"

Started at 19:20:35

. hshaz 'varsaleU', id(codind) $\operatorname{seq}(j) \mathrm{d}$ (exit) nmp(2) difficult

(output omitted)

Discrete time PH model, with discrete mixture Number of obs = 568042

Log likelihood $=-122078.61$

LR $\operatorname{chi2()}$

\begin{tabular}{|c|c|c|c|c|c|c|}
\hline exit & Coef. & Std. Err. & $\mathrm{z}$ & $P>|z|$ & {$[95 \%$ Conf. } & Interval] \\
\hline \multicolumn{7}{|l|}{ hazard } \\
\hline Injunemp & 3.614478 & .0420888 & 85.88 & 0.000 & 3.531985 & 3.69697 \\
\hline Injunemp2 & -.9491475 & .0099176 & -95.70 & 0.000 & -.9685857 & -.9297093 \\
\hline month12 & .1622676 & .0306303 & 5.30 & 0.000 & .1022334 & .2223018 \\
\hline month18 & .1378108 & .051428 & 2.68 & 0.007 & .0370137 & .2386079 \\
\hline month24 & .7349434 & .0620328 & 11.85 & 0.000 & .6133612 & .8565255 \\
\hline $\mathrm{ub}$ & -1.285337 & .0850238 & -15.12 & 0.000 & -1.451981 & -1.118693 \\
\hline ubxlnjunemp & .5991179 & .0452117 & 13.25 & 0.000 & .5105046 & .6877312 \\
\hline female & -.2608074 & .0143061 & -18.23 & 0.000 & -.2888467 & -.232768 \\
\hline age16tv & .1813956 & .0079181 & 22.91 & 0.000 & .1658765 & .1969147 \\
\hline age16tv2 & -.0133667 & .0007284 & -18.35 & 0.000 & -.0147943 & -.011939 \\
\hline educcompul1 & .0902986 & .0193612 & 4.66 & 0.000 & .0523513 & .1282459 \\
\hline educcompul2 & .2061928 & .0143468 & 14.37 & 0.000 & .1780735 & .2343121 \\
\hline inmigra & .1978042 & .0221707 & 8.92 & 0.000 & .1543505 & .241258 \\
\hline unrate & -.0783014 & .0017806 & -43.98 & 0.000 & -.0817912 & -.0748116 \\
\hline andal & .3975506 & .0242093 & 16.42 & 0.000 & .3501011 & .445 \\
\hline aragon & -.3055266 & .0429434 & -7.11 & 0.000 & -.3896941 & -.2213591 \\
\hline astur & -.1925455 & .0484716 & -3.97 & 0.000 & -.2875481 & -.0975429 \\
\hline balear & .1041814 & .0369932 & 2.82 & 0.005 & .0316761 & .1766866 \\
\hline canar & .1055982 & .0322675 & 3.27 & 0.001 & .042355 & .1688413 \\
\hline cantab & -.1365885 & .0591542 & -2.31 & 0.021 & -.2525286 & -.0206484 \\
\hline castman & -.0313481 & .0308196 & -1.02 & 0.309 & -.0917533 & .0290572 \\
\hline castleon & -.0867692 & .0323628 & -2.68 & 0.007 & -.150199 & -.0233393 \\
\hline valenc & .0931611 & .0235731 & 3.95 & 0.000 & .0469587 & .1393635 \\
\hline extrem & .2210849 & .0479023 & 4.62 & 0.000 & .1271981 & .3149717 \\
\hline galic & -.1072982 & .0294785 & -3.64 & 0.000 & -.165075 & -.0495214 \\
\hline murcia & .0607846 & .0389268 & 1.56 & 0.118 & -.0155104 & .1370797 \\
\hline navarr & -.3874214 & .0714272 & -5.42 & 0.000 & -.5274161 & -.2474268 \\
\hline vasco & -.2923951 & .04202 & -6.96 & 0.000 & -.3747527 & -.2100375 \\
\hline rioja & -.1261426 & .0740177 & -1.70 & 0.088 & -.2712147 & .0189295 \\
\hline _cons & -5.159464 & .0520466 & -99.13 & 0.000 & -5.261473 & -5.057454 \\
\hline \multicolumn{7}{|l|}{$\mathrm{m} 2$} \\
\hline _cons & 3.532398 & .0322319 & 109.59 & 0.000 & 3.469225 & 3.595571 \\
\hline \multicolumn{7}{|l|}{ logitp2 } \\
\hline _cons & -.9266268 & .0159517 & -58.09 & 0.000 & -.9578916 & -.8953621 \\
\hline Prob. Type 1 & .7163904 & .003241 & 221.04 & 0.000 & .7099955 & .7226995 \\
\hline Prob. Type 2 & .2836096 & .003241 & 87.51 & 0.000 & .2773005 & .2900045 \\
\hline
\end{tabular}

Note: $\mathrm{m} 1=0$

. display "Finished at \$S_TIME"

Finished at 19:42:55 
Table 1: Estimation of unispell duration models (Sample size: 568,042 observations)

\begin{tabular}{lccc}
\hline \hline & \multicolumn{3}{c}{ Time (hh:mm:ss) } \\
\hline & hshaz \\
\hline Two mass-points & $19: 20: 35$ & $19: 42: 55$ & $0: 22: 20$ \\
Three mass-points & $19: 44: 08$ & $20: 27: 16$ & $0: 43: 08$ \\
\hline & \multicolumn{3}{c}{ hshaz2 } \\
\hline & Start time & Finish time & Duration \\
\hline Two mass-points & $19: 19: 53$ & $19: 20: 35$ & $0: 00: 42$ \\
Three mass-points & $19: 42: 55$ & $19: 44: 08$ & $0: 01: 13$ \\
\hline \hline
\end{tabular}

Table 1 reports time spent by running both hshaz and hshaz2 commands to achieve the convergence of the fitted duration models mentioned above, with two and three mass-points, respectively. ${ }^{11}$ Results of Table 1 highlight two relevant differences between hshaz2 and hshaz commands: First, hshaz2 provides a significant reduction in time required to achieve the convengence: to fit a two mass-points model, hshaz spends twenty two minutes and twenty seconds, while hshaz2 spends only fourty two seconds, which means twenty eight minutes less. And, second, unlike hshaz2, time required by hshaz to achieve the convergence strongly depends on the number of points of support especified by command's user: hshaz needs fourty three minutes to fit a three mass-points model, while hshaz2 spends only one minute and thirteen one seconds.

In order to show the convergence process followed by running both hshaz and hshaz2 commands, Figures 1 and 2 plot the log-likelihood values taken at each iteration by hshaz and hshaz2 commands during the convergence process of the estimation of two mass-points and three mass-points unispell models, respectively. As can be seen in Figures 1 and 2, the values taken by the loglikelihood functions of hshaz and hshaz2 at first iterations slightly differ, but when they aproximate to the maximum, the two log-likelihood functions converge to the same value: $-122,078.61$ for two mass-points models, and -121,861.5 for three mass-points models.

\footnotetext{
${ }^{11}$ For this specific sample of youth unemployed workers, the identification of unobserved heterogeneity is not possible when more than three mass-points are specified, which leads to not achieve convergence, neither running hshaz, nor hshaz2 commands. This is the reason why only results from two and three mass-points duration models are shown in Table 1 .
} 


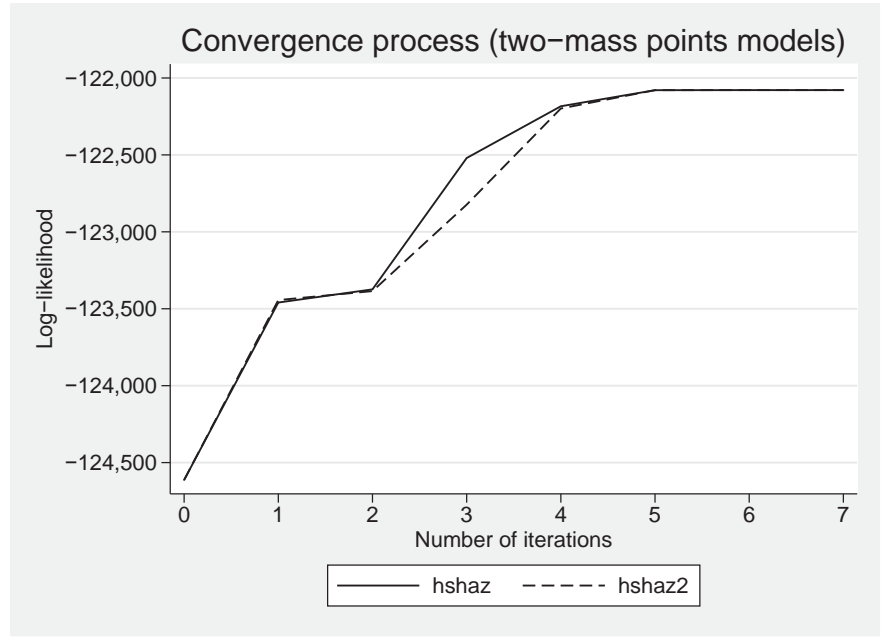

Figure 1: Iteration process of unispell duration models estimation (two masspoints)

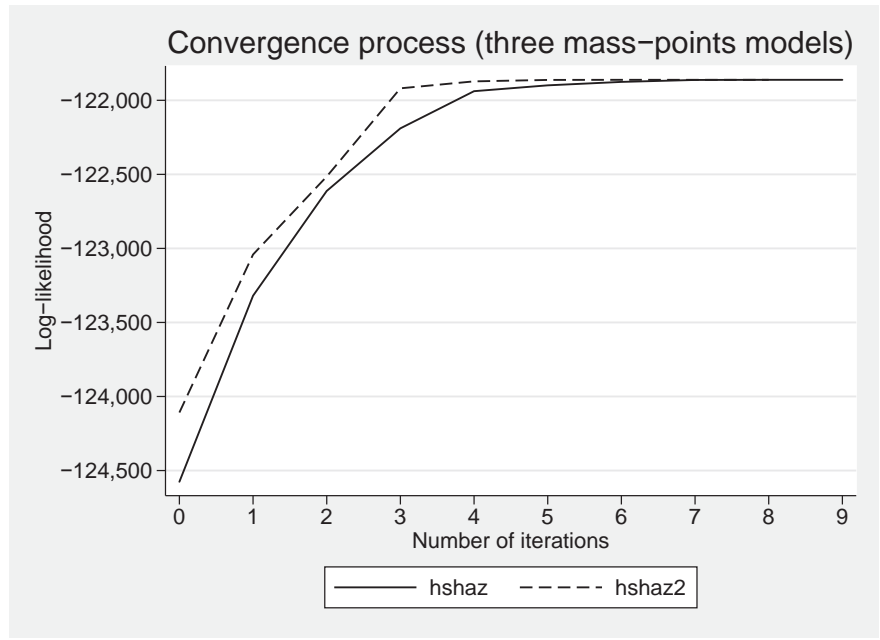

Figure 2: Iteration process of unispell duration models estimation (three masspoints) 
Table 2: Estimation of multispell duration models using hshaz2 (Sample size: $1,547,507$ observations)

\begin{tabular}{lccc}
\hline \hline & \multicolumn{3}{c}{ Time (hh:mm:ss) } \\
\hline & Start time & Finish time & Duration \\
\hline Two mass-points & $20: 27: 16$ & $20: 28: 33$ & $0: 01: 17$ \\
Three mass-points & $20: 28: 33$ & $20: 30: 50$ & $0: 02: 17$ \\
\hline
\end{tabular}

\subsection{Fitting multispell duration models using hshaz2}

As was previously mentioned, hshaz2 allows for the estimation of multispell duration models, by which individuals may be at risk of exiting more than once. And this feature implies, in our example, that each individual may experience several unemployment episodes. Time saving advantages given by hshaz2 takes special interest in multispell duration models because of the increase of the number of observations of the estimation sample, and therefore, the increase in required estimation time that it implies. To highlight the importance of this, a multispell duration model is fitted using another version of the sample, in which multiple unemployment spells are observed for each individual. This sample has $1,547,507$ observations. The number of indivuals is 44,077 , and the total number of unemployment spells is 146,851 , that means an average number of spells per individual of roughly 3.33. The econometric especification includes the same covariates specified by the rest of the models estimated in the previous Section.

Table 2 reports time spent by hshaz 2 to achieve convergence for the two estimated models: the first one includes two points of support, and the second one specifies three points of support. Estimation output at final Appendix reports detailed estimation output.

\section{Reparameterization of mass-points probabilities}

Functional form followed by hshaz command to compute mass-points probability parameters $\pi_{j}$ is a Logit, regardless of the number of points of support specified by the command's user, whereas hshaz2 computes the mass-points probabilities using a Multinomial Logit. For the estimation of two mass-points models, as only one parameter $p_{2}$ must be estimated, both hshaz and hshaz2 compute the values of mass probability parameters using the same functional form, with $\pi_{2}=\frac{e^{p 2}}{1+e^{p^{2}}}$ and $\pi_{1}=1-\pi_{2}$, providing the same coefficient estimates of $\hat{\pi}_{2}$ and $\hat{\pi}_{1}$, as well as for their standard errors. However, when more than two points of support are especified, functional forms used by hshaz and hshaz2 to compute the values of mass probability parameters are different. For example, for three mass-points models, hshaz computes $\pi_{2}=\frac{e^{p 2}}{1+e^{p 2}}, \pi_{3}=\frac{e^{p 3}}{1+e^{p 3}}$ and $\pi_{1}=1-\pi_{2}-\pi_{3} ;$ whereas hshaz2 computes $\pi_{2}=\frac{e^{p 2}}{1+e^{p 2}+e^{p 3}}, \pi_{3}=\frac{e^{p 3}}{1+e^{p 2}+e^{p 3}}$ 
and $\pi_{1}=1-\pi_{2}-\pi_{3}$.

This explians the differences found in mass-probability parameters estimates, given by $\hat{p}_{2}, \hat{p}_{3}, \hat{\pi}_{2}$ and $\hat{\pi}_{3}$, depending on whether have been estimated using hshaz or hshaz2. Thus, as can be seen in the estimation output of Appendix (in pages 18 to 21), estimated values of $p_{2}$ and $p_{3}$ provided by hshaz (hshaz2) are $-0.915(-0.629)$ and $-1.533(-1.105)$, respectively. And standard errors of $p_{2}$ and $p_{3}$ provided by hshaz (hshaz2) are 0.016 (0.025) and 0.081 (0.087), respectively. Both hshaz and hshaz2 provide $p_{2}$ and $p_{3}$ coefficients statistically significant at $1 \%$ level. ${ }^{12}$ However, estimated values of mass probability parameters, given by $\hat{p}_{2}, \hat{p}_{3}$ and $\hat{p}_{1}$, do not show significant differences.

\section{Conclusion}

hshaz2 command provides the programming of gradient vector and Hessian matrix of the log-likelihood function of hshaz command, written by professor Stephen Jenkins. The programming of the algebraic expressions of both first and second derivatives allows to use $\mathrm{d} 2 \mathrm{ml}$ method to achieve faster estimations of discrete time proportional hazard models with unobserved heterogeneity. Furthermore, in contrast to hshaz, hshaz2 allows for the estimation of multispell duration models, by which individuals may be observed at risk of exiting more than once. The gains achieved in saving time provided by hshaz2 are stricky: Estimation results show that, on a sample size of 568,042 observations, hshaz2 (hshaz) spends $0.42(22.2)$ and 1.13 (43.08) minutes to achieve the convergence of a duration model with two and three points of support, respectively. Finally, The gains in estimation time involved by hshaz2 command takes special relevance as the sample size increases: Using a sample with 1,547,507 observations, the estimation of a multispell duration model with two (three) points of support requires 1.17 (2.17) minutes.

\footnotetext{
${ }^{12}$ To estimate the standard errors of mass probability parameters, hshaz2 provides to diparm command the algebraric expressions of first order derivatives of each $\pi_{j}=\frac{e^{p_{j}}}{1+\sum_{l=2}^{L} e^{p_{l}}}$, for each $j=1,2, \ldots, P$, with respect to each $p_{l}$, with $l=2,3, \ldots, P$
} 


\section{References}

[Gould et al., 2010]

Gould, W., Pitblado, J. and Poi, B., Maximum Likelihood Estimation with Stata, Fourth Edition, Stata Press, 2010.

[Heckman and Singer, 1984] Heckman, J. J. And Singer, B., A Method for Minimizing the Impact of the Distributional Assumptions in Econometric Models for Duration Data, Econometrica, Vol. 52, pp. 271-320.

[Arranz and García-Serrano, 2011] Arranz, J.M. and García-Serrano, C. (2011) Are the MCVL tax data useful? Ideas for mining, Hacienda Pública Española, Vol. 199(4), 151-186.

[Lapuerta, 2010]

LAPUerta, I. (2010) Claves para el trabajo con la Muestra Continua de Vidas Laborales, DemoSoc working paper (2010-37), Universitat Pompeu Fabra

[García-Pérez, 2008]

García-PÉrez, J.I., 2008 La Muestra Continua de Vidas Laborales: Una guía de uso para el anlisis de transiciones, Revista de Economía Aplicada, N. E-1, Vol. XVI, pp. 5-28.

[Jenkins, 2005]

Jenkins, S., 2005 Survival Analysis, manuscript. 


\section{Appendix}

\section{Estimation output of fitting an unispell two mass-points model using hshaz2 and hshaz}

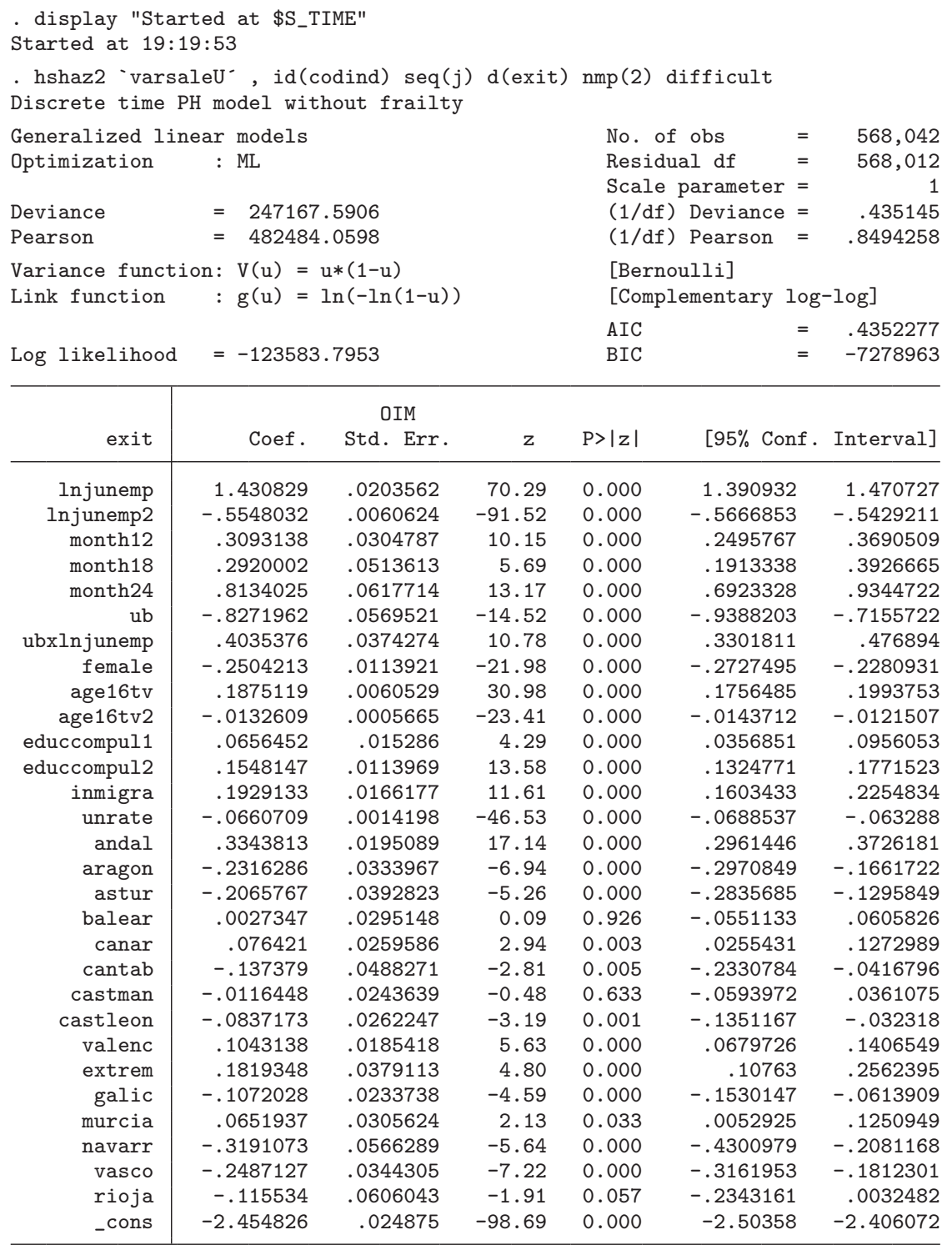


(output omitted)

Discrete time PH model, with discrete mixture

Log likelihood $=-122078.61$
Number of obs= LR chi2() Prob > chi2
568042 $=$

\begin{tabular}{|c|c|c|c|c|c|c|}
\hline exit & Coef. & Std. Err. & $z$ & $P>|z|$ & {$[95 \%$ Conf. } & Interval] \\
\hline \multicolumn{7}{|l|}{ hazard } \\
\hline Injunemp & 3.614478 & .0420878 & 85.88 & 0.000 & 3.531987 & 3.696968 \\
\hline Injunemp2 & -.9491475 & .0099174 & -95.71 & 0.000 & -.9685853 & -.9297097 \\
\hline month12 & .1622685 & .0306302 & 5.30 & 0.000 & .1022344 & .2223027 \\
\hline month18 & .1378142 & .051428 & 2.68 & 0.007 & .0370172 & .2386111 \\
\hline month24 & .7349469 & .0620328 & 11.85 & 0.000 & .6133649 & .8565289 \\
\hline $\mathrm{ub}$ & -1.28535 & .0850207 & -15.12 & 0.000 & -1.451988 & -1.118713 \\
\hline ubxlnjunemp & .5991264 & .04521 & 13.25 & 0.000 & .5105164 & .6877363 \\
\hline female & -.2608072 & .0143061 & -18.23 & 0.000 & -.2888466 & -.2327679 \\
\hline age16tv & .1813952 & .0079179 & 22.91 & 0.000 & .1658763 & .196914 \\
\hline age16tv2 & -.0133666 & .0007284 & -18.35 & 0.000 & -.0147943 & -.011939 \\
\hline educcompul1 & .090299 & .0193612 & 4.66 & 0.000 & .0523517 & .1282463 \\
\hline educcompul2 & .2061935 & .0143468 & 14.37 & 0.000 & .1780742 & .2343127 \\
\hline inmigra & .1978054 & .0221707 & 8.92 & 0.000 & .1543517 & .2412591 \\
\hline unrate & -.0783014 & .0017806 & -43.98 & 0.000 & -.0817913 & -.0748116 \\
\hline andal & .3975539 & .0242093 & 16.42 & 0.000 & .3501046 & .4450033 \\
\hline aragon & -.3055231 & .0429434 & -7.11 & 0.000 & -.3896905 & -.2213556 \\
\hline astur & -.1925411 & .0484716 & -3.97 & 0.000 & -.2875437 & -.0975386 \\
\hline balear & .104185 & .0369932 & 2.82 & 0.005 & .0316797 & .1766903 \\
\hline canar & .1056043 & .0322674 & 3.27 & 0.001 & .0423613 & .1688473 \\
\hline cantab & -.1365828 & .0591541 & -2.31 & 0.021 & -.2525228 & -.0206428 \\
\hline castman & -.0313442 & .0308195 & -1.02 & 0.309 & -.0917493 & .029061 \\
\hline castleon & -.0867659 & .0323628 & -2.68 & 0.007 & -.1501957 & -.023336 \\
\hline valenc & .0931641 & .0235731 & 3.95 & 0.000 & .0469617 & .1393665 \\
\hline extrem & .2210893 & .0479023 & 4.62 & 0.000 & .1272026 & .3149761 \\
\hline galic & -.1072949 & .0294785 & -3.64 & 0.000 & -.1650717 & -.0495181 \\
\hline murcia & .0607897 & .0389267 & 1.56 & 0.118 & -.0155053 & .1370846 \\
\hline navarr & -.3874108 & .0714269 & -5.42 & 0.000 & -.5274051 & -.2474166 \\
\hline vasco & -.2923917 & .0420199 & -6.96 & 0.000 & -.3747493 & -.2100341 \\
\hline rioja & -.1261293 & .0740175 & -1.70 & 0.088 & -.2712009 & .0189422 \\
\hline _cons & -5.159466 & .0520456 & -99.13 & 0.000 & -5.261473 & -5.057458 \\
\hline \multicolumn{7}{|l|}{$\mathrm{m} 2$} \\
\hline _cons & 3.532398 & .0322314 & 109.59 & 0.000 & 3.469226 & 3.59557 \\
\hline \multicolumn{7}{|l|}{ logitp2 } \\
\hline _cons & -.9266265 & .0159517 & -58.09 & 0.000 & -.9578912 & -.8953618 \\
\hline Prob. Type 1 & .7163904 & .003241 & 221.04 & 0.000 & .7099954 & .7226994 \\
\hline Prob. Type 2 & .2836096 & .003241 & 87.51 & 0.000 & .2773006 & .2900046 \\
\hline
\end{tabular}

Note: $\mathrm{m} 1=0$

. display "Finished at \$S_TIME"

Finished at 19:20:35 
. display "Started at \$S_TIME"

Started at 19:20:35

. hshaz 'varsaleU', id(codind) seq(j) d(exit) nmp(2) difficult

Discrete time PH model without frailty

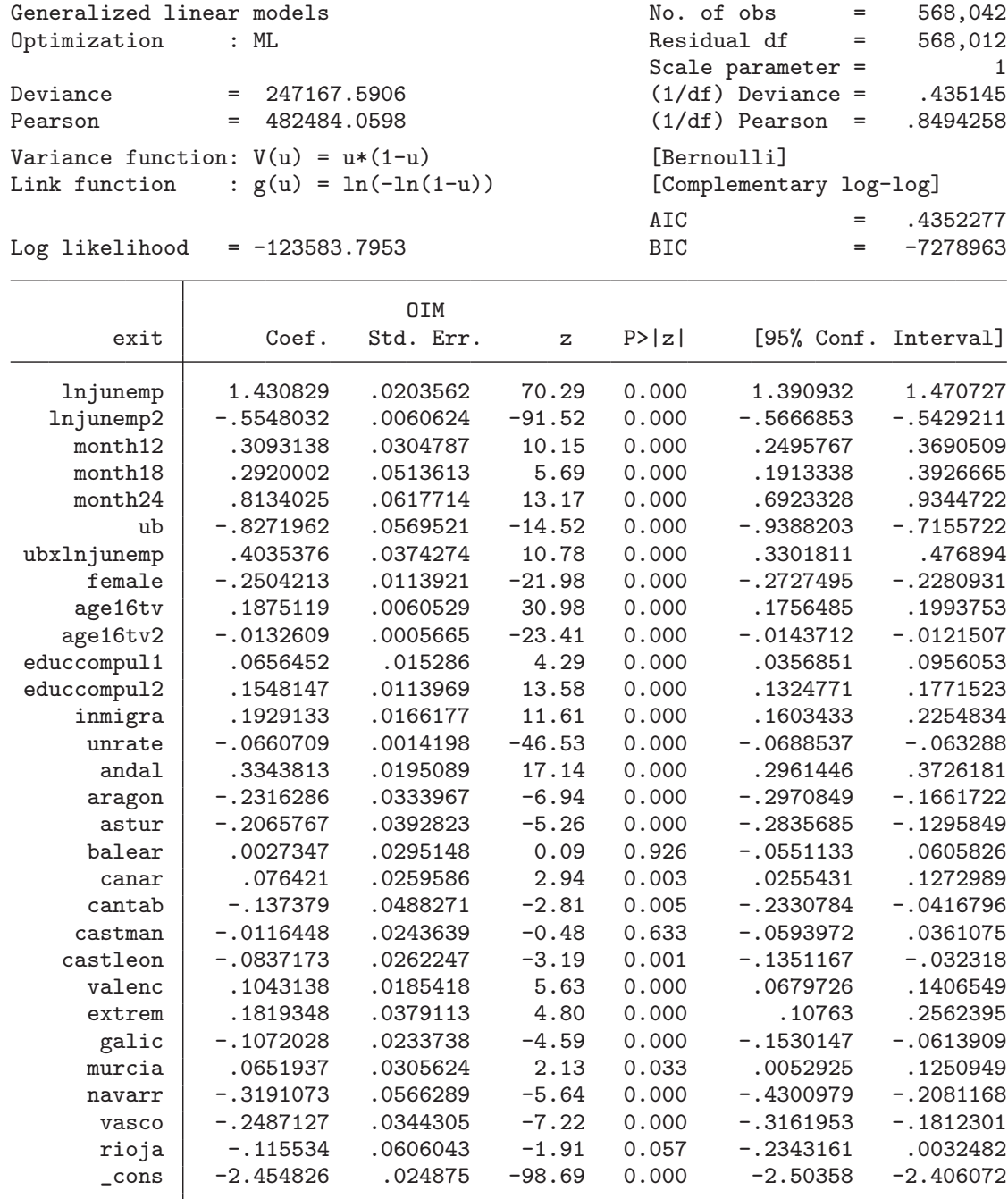


(output omitted)

Discrete time PH model, with discrete mixture

Log likelihood $=-122078.61$
Number of obs LR chi2() Prob > chi2

\begin{tabular}{|c|c|c|c|c|c|c|}
\hline exit & Coef. & Std. Err. & $z$ & $P>|z|$ & {$[95 \%$ Conf. } & Interval] \\
\hline \multicolumn{7}{|l|}{ hazard } \\
\hline Injunemp & 3.614478 & .0420888 & 85.88 & 0.000 & 3.531985 & 3.69697 \\
\hline Injunemp2 & -.9491475 & .0099176 & -95.70 & 0.000 & -.9685857 & -.9297093 \\
\hline month12 & .1622676 & .0306303 & 5.30 & 0.000 & .1022334 & .2223018 \\
\hline month18 & .1378108 & .051428 & 2.68 & 0.007 & .0370137 & .2386079 \\
\hline month24 & .7349434 & .0620328 & 11.85 & 0.000 & .6133612 & .8565255 \\
\hline $\mathrm{ub}$ & -1.285337 & .0850238 & -15.12 & 0.000 & -1.451981 & -1.118693 \\
\hline ubxlnjunemp & .5991179 & .0452117 & 13.25 & 0.000 & .5105046 & .6877312 \\
\hline female & -.2608074 & .0143061 & -18.23 & 0.000 & -.2888467 & -.232768 \\
\hline age16tv & .1813956 & .0079181 & 22.91 & 0.000 & .1658765 & .1969147 \\
\hline age16tv2 & -.0133667 & .0007284 & -18.35 & 0.000 & -.0147943 & -.011939 \\
\hline educcompul1 & .0902986 & .0193612 & 4.66 & 0.000 & .0523513 & .1282459 \\
\hline educcompul2 & .2061928 & .0143468 & 14.37 & 0.000 & .1780735 & .2343121 \\
\hline inmigra & .1978042 & .0221707 & 8.92 & 0.000 & .1543505 & .241258 \\
\hline unrate & -.0783014 & .0017806 & -43.98 & 0.000 & -.0817912 & -.0748116 \\
\hline andal & .3975506 & .0242093 & 16.42 & 0.000 & .3501011 & .445 \\
\hline aragon & -.3055266 & .0429434 & -7.11 & 0.000 & -.3896941 & -.2213591 \\
\hline astur & -.1925455 & .0484716 & -3.97 & 0.000 & -.2875481 & -.0975429 \\
\hline balear & .1041814 & .0369932 & 2.82 & 0.005 & .0316761 & .1766866 \\
\hline canar & .1055982 & .0322675 & 3.27 & 0.001 & .042355 & .1688413 \\
\hline cantab & -.1365885 & .0591542 & -2.31 & 0.021 & -.2525286 & -.0206484 \\
\hline castman & -.0313481 & .0308196 & -1.02 & 0.309 & -.0917533 & .0290572 \\
\hline castleon & -.0867692 & .0323628 & -2.68 & 0.007 & -.150199 & -.0233393 \\
\hline valenc & .0931611 & .0235731 & 3.95 & 0.000 & .0469587 & .1393635 \\
\hline extrem & .2210849 & .0479023 & 4.62 & 0.000 & .1271981 & .3149717 \\
\hline galic & -.1072982 & .0294785 & -3.64 & 0.000 & -.165075 & -.0495214 \\
\hline murcia & .0607846 & .0389268 & 1.56 & 0.118 & -.0155104 & .1370797 \\
\hline navarr & -.3874214 & .0714272 & -5.42 & 0.000 & -.5274161 & -.2474268 \\
\hline vasco & -.2923951 & .04202 & -6.96 & 0.000 & -.3747527 & -.2100375 \\
\hline rioja & -.1261426 & .0740177 & -1.70 & 0.088 & -.2712147 & .0189295 \\
\hline _cons & -5.159464 & .0520466 & -99.13 & 0.000 & -5.261473 & -5.057454 \\
\hline \multicolumn{7}{|l|}{$\mathrm{m} 2$} \\
\hline _cons & 3.532398 & .0322319 & 109.59 & 0.000 & 3.469225 & 3.595571 \\
\hline \multicolumn{7}{|l|}{ logitp2 } \\
\hline _cons & -.9266268 & .0159517 & -58.09 & 0.000 & -.9578916 & -.8953621 \\
\hline Prob. Type 1 & .7163904 & .003241 & 221.04 & 0.000 & .7099955 & .7226995 \\
\hline Prob. Type 2 & .2836096 & .003241 & 87.51 & 0.000 & .2773005 & .2900045 \\
\hline
\end{tabular}

Note: $\mathrm{m} 1=0$

. display "Finished at \$S_TIME"

Finished at 19:42:55 


\section{Estimation output of fitting an unispell three mass-points model using hshaz2 and hshaz}

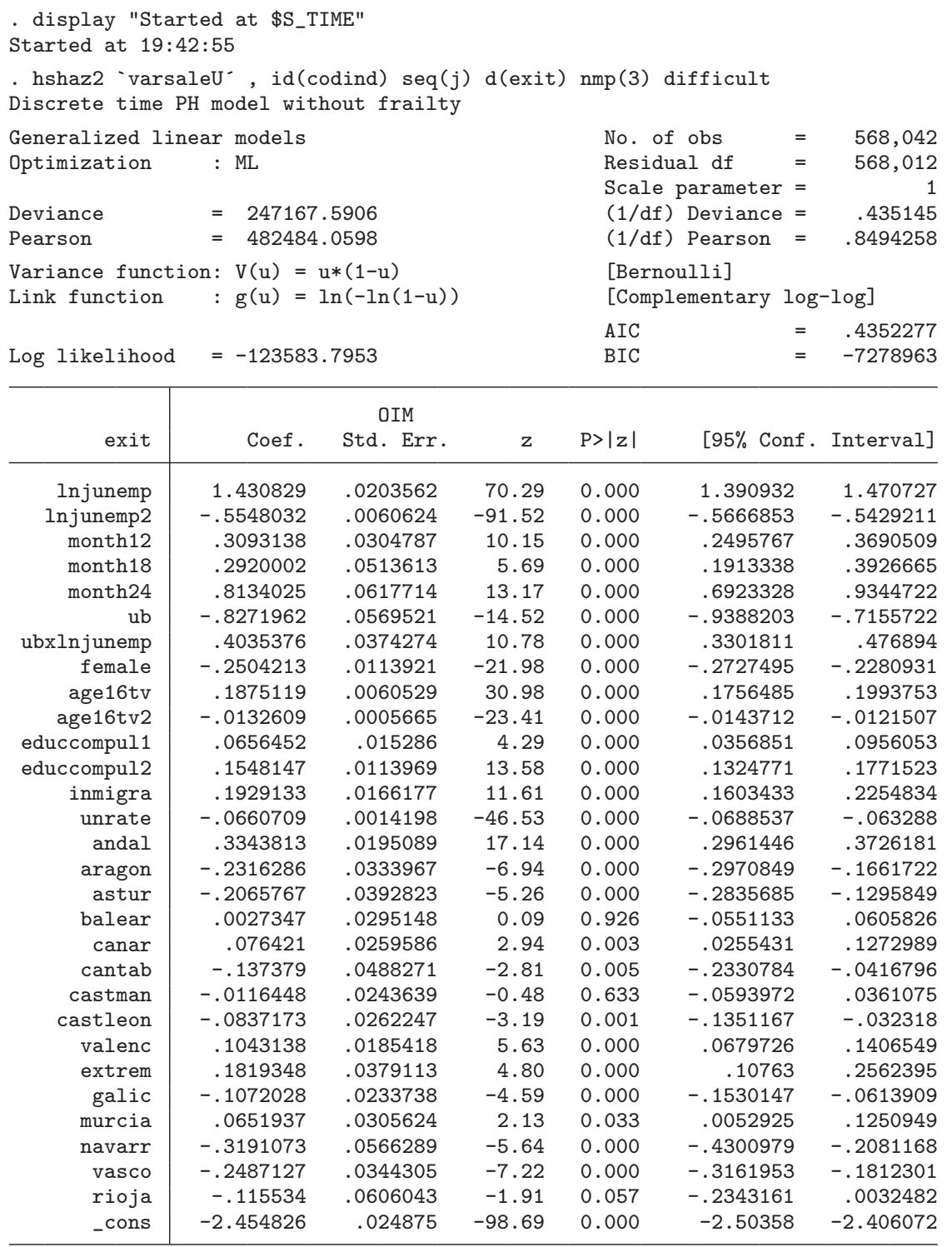


(output omitted)

\begin{tabular}{|c|c|c|c|c|c|c|}
\hline exit & Coef. & Std. Err. & z & $P>|z|$ & {$[95 \%$ Conf. } & Interval] \\
\hline \multicolumn{7}{|l|}{ hazard } \\
\hline Injunemp & 3.498714 & .0440098 & 79.50 & 0.000 & 3.412457 & 3.584972 \\
\hline Injunemp2 & -.8344097 & .0114636 & -72.79 & 0.000 & -.856878 & -.8119415 \\
\hline month12 & .1728664 & .0310214 & 5.57 & 0.000 & .1120656 & .2336672 \\
\hline month18 & .171937 & .0517658 & 3.32 & 0.001 & .0704779 & .2733961 \\
\hline month24 & .8131917 & .0624735 & 13.02 & 0.000 & .6907459 & .9356375 \\
\hline $\mathrm{ub}$ & -1.369189 & .08402 & -16.30 & 0.000 & -1.533865 & -1.204512 \\
\hline ubxlnjunemp & .544226 & .0486218 & 11.19 & 0.000 & .4489291 & .6395229 \\
\hline female & -.3663279 & .0192127 & -19.07 & 0.000 & -.403984 & -.3286717 \\
\hline age16tv & .2851709 & .0104771 & 27.22 & 0.000 & .2646363 & .3057056 \\
\hline age16tv2 & -.0195095 & .0009353 & -20.86 & 0.000 & -.0213427 & -.0176763 \\
\hline educcompul1 & .1166009 & .0260306 & 4.48 & 0.000 & .065582 & .1676199 \\
\hline educcompul2 & .2443288 & .0190789 & 12.81 & 0.000 & .2069349 & .2817227 \\
\hline inmigra & .4532836 & .0349271 & 12.98 & 0.000 & .3848278 & .5217394 \\
\hline unrate & -.1002291 & .0023965 & -41.82 & 0.000 & -.1049261 & -.0955322 \\
\hline andal & .4951261 & .0331679 & 14.93 & 0.000 & .4301183 & .5601339 \\
\hline aragon & -.3788273 & .0558053 & -6.79 & 0.000 & -.4882037 & -.269451 \\
\hline astur & -.2838207 & .0657935 & -4.31 & 0.000 & -.4127736 & -.1548679 \\
\hline balear & .1441218 & .0492659 & 2.93 & 0.003 & .0475624 & .2406811 \\
\hline canar & .0761471 & .0427015 & 1.78 & 0.075 & -.0075462 & .1598404 \\
\hline cantab & -.1574583 & .0770308 & -2.04 & 0.041 & -.3084358 & -.0064807 \\
\hline castman & .0211891 & .042082 & 0.50 & 0.615 & -.0612901 & .1036684 \\
\hline castleon & -.1217481 & .0420095 & -2.90 & 0.004 & -.2040852 & -.039411 \\
\hline valenc & .1208921 & .0317378 & 3.81 & 0.000 & .0586872 & .1830971 \\
\hline extrem & .2780232 & .0625915 & 4.44 & 0.000 & .1553461 & .4007003 \\
\hline galic & -.1282771 & .0394518 & -3.25 & 0.001 & -.2056012 & -.050953 \\
\hline murcia & .0963948 & .0517655 & 1.86 & 0.063 & -.0050638 & .1978534 \\
\hline navarr & -.514514 & .0934307 & -5.51 & 0.000 & -.6976348 & -.3313933 \\
\hline vasco & -.4258417 & .0551267 & -7.72 & 0.000 & -.533888 & -.3177953 \\
\hline rioja & -.1639572 & .1025683 & -1.60 & 0.110 & -.3649875 & .037073 \\
\hline _cons & -4.985959 & .0561667 & -88.77 & 0.000 & -5.096044 & -4.875874 \\
\hline \multicolumn{7}{|l|}{$\mathrm{m} 2$} \\
\hline _cons & 3.33153 & .0341016 & 97.69 & 0.000 & 3.264692 & 3.398368 \\
\hline \multicolumn{7}{|l|}{$\mathrm{m} 3$} \\
\hline _cons & -1.853107 & .0678011 & -27.33 & 0.000 & -1.985995 & -1.72022 \\
\hline \multicolumn{7}{|l|}{ logitp2 } \\
\hline _cons & -.6293778 & .0251716 & -25.00 & 0.000 & -.6787132 & -.5800423 \\
\hline \multicolumn{7}{|l|}{ logitp3 } \\
\hline _cons & -1.105979 & .0877127 & -12.61 & 0.000 & -1.277892 & -.9340649 \\
\hline Prob. Type 1 & .5365353 & .011589 & 46.30 & 0.000 & .5137611 & .5591582 \\
\hline Prob. Type 2 & .2859322 & .0033266 & 85.95 & 0.000 & .279457 & .2924965 \\
\hline Prob. Type 3 & .1775325 & .0118536 & 14.98 & 0.000 & .155478 & .2019673 \\
\hline
\end{tabular}

Note: $\mathrm{m} 1=0$

. display "Finished at \$S_TIME"

Finished at 19:44:08 
. display "Started at \$S_TIME" Started at 19:44:08

. hshaz 'varsaleU', id(codind) seq(j) d(exit) $n m p(3)$ difficult Discrete time PH model without frailty

$\begin{array}{ll}\text { Generalized linear models } \\ \text { Optimization } & \text { : ML } \\ \text { Deviance } & =247167.5906 \\ \text { Pearson } & =482484.0598\end{array}$

2484.0598

Variance function: $\mathrm{V}(\mathrm{u})=\mathrm{u} *(1-\mathrm{u})$

Link function : $g(u)=\ln (-\ln (1-u))$

No. of obs $=568,042$

Residual df $=568,012$

Scale parameter $=1$

$(1 / \mathrm{df})$ Deviance $=.435145$

$(1 / \mathrm{df})$ Pearson $=.8494258$

[Bernoulli]

[Complementary log-log]

Log likelihood $=-123583.7953$

AIC $\quad=.4352277$

\begin{tabular}{r|rrrrrr}
\hline & \multicolumn{7}{c}{ OIM } & & & \\
exit & Coef. & Std. Err. & $\mathrm{z}$ & $\mathrm{P}>|\mathrm{z}|$ & [95\% Conf. & Interval] \\
\hline Injunemp & 1.430829 & .0203562 & 70.29 & 0.000 & 1.390932 & 1.470727 \\
Injunemp2 & -.5548032 & .0060624 & -91.52 & 0.000 & -.5666853 & -.5429211 \\
month12 & .3093138 & .0304787 & 10.15 & 0.000 & .2495767 & .3690509 \\
month18 & .2920002 & .0513613 & 5.69 & 0.000 & .1913338 & .3926665 \\
month24 & .8134025 & .0617714 & 13.17 & 0.000 & .6923328 & .9344722 \\
ub & -.8271962 & .0569521 & -14.52 & 0.000 & -.9388203 & -.7155722 \\
ubxlnjunemp & .4035376 & .0374274 & 10.78 & 0.000 & .3301811 & .476894 \\
female & -.2504213 & .0113921 & -21.98 & 0.000 & -.2727495 & -.2280931 \\
age16tv & .1875119 & .0060529 & 30.98 & 0.000 & .1756485 & .1993753 \\
age16tv2 & -.0132609 & .0005665 & -23.41 & 0.000 & -.0143712 & -.0121507 \\
educcompul1 & .0656452 & .015286 & 4.29 & 0.000 & .0356851 & .0956053 \\
educcompul2 & .1548147 & .0113969 & 13.58 & 0.000 & .1324771 & .1771523 \\
inmigra & .1929133 & .0166177 & 11.61 & 0.000 & .1603433 & .2254834 \\
unrate & -.0660709 & .0014198 & -46.53 & 0.000 & -.0688537 & -.063288 \\
andal & .3343813 & .0195089 & 17.14 & 0.000 & .2961446 & .3726181 \\
aragon & -.2316286 & .0333967 & -6.94 & 0.000 & -.2970849 & -.1661722 \\
astur & -.2065767 & .0392823 & -5.26 & 0.000 & -.2835685 & -.1295849 \\
balear & .0027347 & .0295148 & 0.09 & 0.926 & -.0551133 & .0605826 \\
canar & .076421 & .0259586 & 2.94 & 0.003 & .0255431 & .1272989 \\
cantab & -.137379 & .0488271 & -2.81 & 0.005 & -.2330784 & -.0416796 \\
castman & -.0116448 & .0243639 & -0.48 & 0.633 & -.0593972 & .0361075 \\
castleon & -.0837173 & .0262247 & -3.19 & 0.001 & -.1351167 & -.032318 \\
valenc & .1043138 & .0185418 & 5.63 & 0.000 & .0679726 & .1406549 \\
extrem & .1819348 & .0379113 & 4.80 & 0.000 & .10763 & .2562395 \\
galic & -.1072028 & .0233738 & -4.59 & 0.000 & -.1530147 & -.0613909 \\
murcia & .0651937 & .0305624 & 2.13 & 0.033 & .0052925 & .1250949 \\
navarr & -.3191073 & .0566289 & -5.64 & 0.000 & -.4300979 & -.2081168 \\
vasco & -.2487127 & .0344305 & -7.22 & 0.000 & -.3161953 & -.1812301 \\
rioja & -.115534 & .0606043 & -1.91 & 0.057 & -.2343161 & .0032482 \\
_cons & -2.454826 & .024875 & -98.69 & 0.000 & -2.50358 & -2.406072 \\
\hline & & & & & & \\
\hline
\end{tabular}


(output omitted)

Discrete time PH model, with discrete mixture

Number of obs

LR $\operatorname{chi2}()$

Log likelihood $=-121861.5$

Prob > chi2

\begin{tabular}{|c|c|c|c|c|c|c|}
\hline exit & Coef. & Std. Err. & $\mathrm{z}$ & $P>|z|$ & {$[95 \%$ Conf } & Interval] \\
\hline \multicolumn{7}{|l|}{ hazard } \\
\hline lnjunemp & 3.498702 & .0440091 & 79.50 & 0.000 & 3.412446 & 3.584959 \\
\hline Injunemp2 & -.8344044 & .0114635 & -72.79 & 0.000 & -.8568725 & -.8119363 \\
\hline month12 & .1728618 & .0310213 & 5.57 & 0.000 & .1120613 & .2336623 \\
\hline month18 & .1719335 & .0517656 & 3.32 & 0.001 & .0704749 & .2733922 \\
\hline month24 & .8131908 & .0624731 & 13.02 & 0.000 & .6907457 & .9356359 \\
\hline $\mathrm{ub}$ & -1.369188 & .0840199 & -16.30 & 0.000 & -1.533864 & -1.204512 \\
\hline ubxlnjunemp & .5442215 & .0486217 & 11.19 & 0.000 & .4489248 & .6395182 \\
\hline female & -.36633 & .0192127 & -19.07 & 0.000 & -.4039861 & -.3286739 \\
\hline age16tv & .2851726 & .0104772 & 27.22 & 0.000 & .2646376 & .3057075 \\
\hline age16tv2 & -.0195095 & .0009353 & -20.86 & 0.000 & -.0213428 & -.0176763 \\
\hline educcompul1 & .1166015 & .0260305 & 4.48 & 0.000 & .0655826 & .1676204 \\
\hline educcompul2 & .244328 & .0190788 & 12.81 & 0.000 & .2069343 & .2817218 \\
\hline inmigra & .4532945 & .034927 & 12.98 & 0.000 & .3848389 & .5217501 \\
\hline unrate & -.1002293 & .0023965 & -41.82 & 0.000 & -.1049263 & -.0955324 \\
\hline andal & .4951238 & .0331676 & 14.93 & 0.000 & .4301164 & .5601312 \\
\hline aragon & -.3788299 & .0558052 & -6.79 & 0.000 & -.4882061 & -.2694537 \\
\hline astur & -.283826 & .0657933 & -4.31 & 0.000 & -.4127785 & -.1548735 \\
\hline balear & .1441224 & .0492658 & 2.93 & 0.003 & .0475631 & .2406817 \\
\hline canar & .0761416 & .0427012 & 1.78 & 0.075 & -.0075511 & .1598343 \\
\hline cantab & -.1574604 & .0770308 & -2.04 & 0.041 & -.3084379 & -.0064829 \\
\hline castman & .0211906 & .042082 & 0.50 & 0.615 & -.0612887 & .1036699 \\
\hline castleon & -.1217498 & .0420094 & -2.90 & 0.004 & -.2040866 & -.0394129 \\
\hline valenc & .1208901 & .0317377 & 3.81 & 0.000 & .0586855 & .1830948 \\
\hline extrem & .27802 & .0625916 & 4.44 & 0.000 & .1553428 & .4006973 \\
\hline galic & -.128278 & .0394517 & -3.25 & 0.001 & -.205602 & -.050954 \\
\hline murcia & .0963935 & .0517655 & 1.86 & 0.063 & -.005065 & .1978519 \\
\hline navarr & -.514519 & .0934308 & -5.51 & 0.000 & -.6976399 & -.3313981 \\
\hline vasco & -.4258472 & .0551265 & -7.72 & 0.000 & -.5338931 & -.3178014 \\
\hline rioja & -.1639663 & .1025687 & -1.60 & 0.110 & -.3649972 & .0370647 \\
\hline _cons & -4.985975 & .0561658 & -88.77 & 0.000 & -5.096058 & -4.875892 \\
\hline \multicolumn{7}{|l|}{$\mathrm{m} 2$} \\
\hline _cons & 3.331543 & .0341009 & 97.70 & 0.000 & 3.264706 & 3.398379 \\
\hline \multicolumn{7}{|l|}{$\mathrm{m} 3$} \\
\hline _cons & -1.853159 & .0677947 & -27.33 & 0.000 & -1.986034 & -1.720284 \\
\hline \multicolumn{7}{|l|}{ logitp2 } \\
\hline _cons & -.915219 & .0162927 & -56.17 & 0.000 & -.9471521 & -.8832858 \\
\hline \multicolumn{7}{|l|}{ logitp3 } \\
\hline -cons & -1.533228 & .0811708 & -18.89 & 0.000 & -1.69232 & -1.374136 \\
\hline Prob. Type 1 & .536545 & .0115873 & 46.30 & 0.000 & .5137742 & .5591644 \\
\hline Prob. Type 2 & .2859331 & .0033266 & 85.95 & 0.000 & .2794579 & .2924973 \\
\hline Prob. Type 3 & .1775219 & .0118516 & 14.98 & 0.000 & .155471 & .2019525 \\
\hline
\end{tabular}

Note: $\mathrm{m} 1=0$

. display "Finished at \$S_TIME"

Finished at 20:27:16 


\section{Estimation output of fitting a multispell two mass-points model using hshaz2}

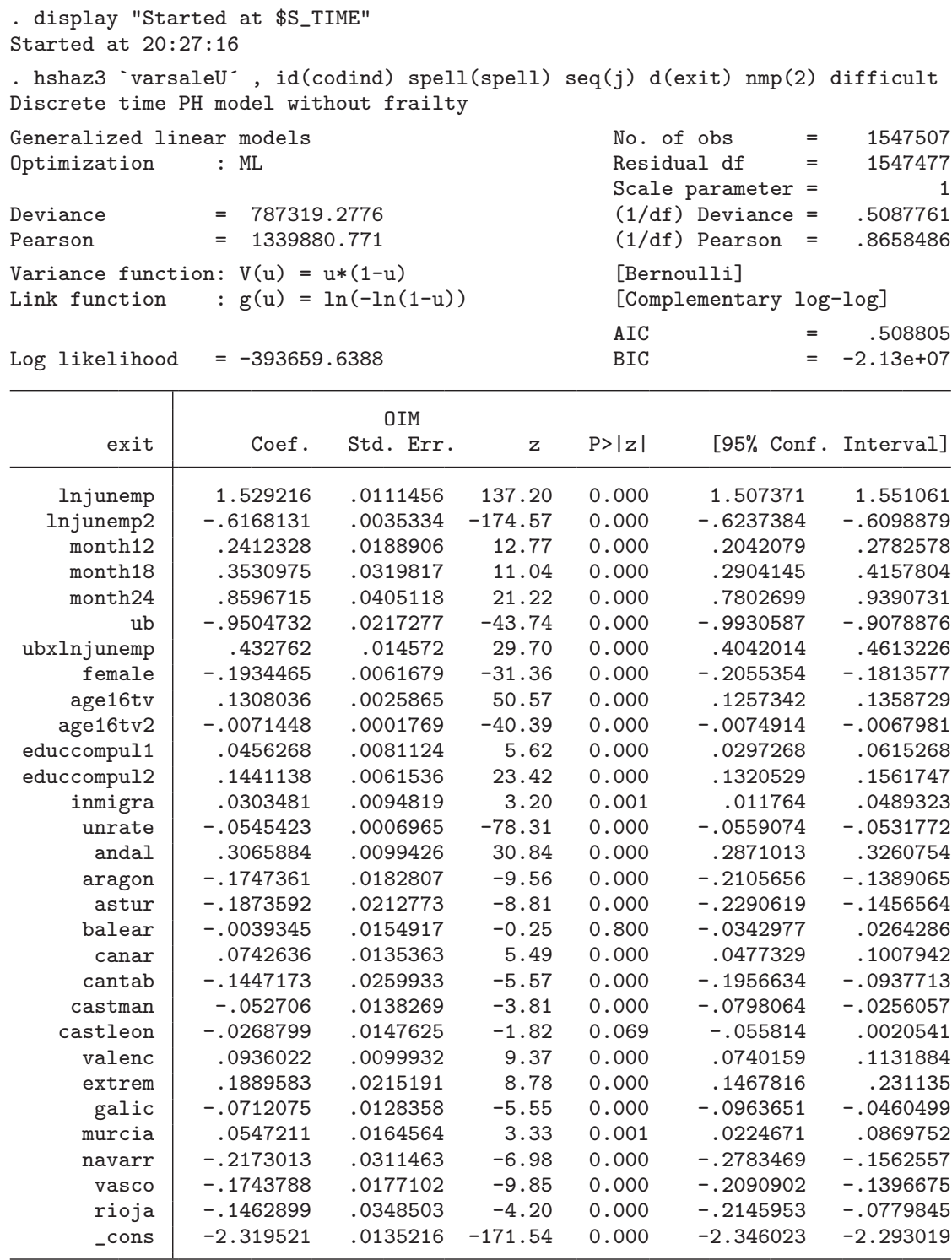

Iteration 0: $\quad \log$ likelihood $=-394287$ (not concave)

Iteration 1: $\quad \log$ likelihood $=-390285.16$

Iteration 2: log likelihood $=-389985.45$

Iteration 3: $\quad \log$ likelihood $=-389666.04$

Iteration 4: $\quad$ log likelihood $=-389660.59$

Iteration 5: log likelihood $=-389660.57$ 
Log likelihood $=-389660.57$

Prob > chi2

\begin{tabular}{|c|c|c|c|c|c|c|}
\hline exit & Coef. & Std. Err. & $z$ & $P>|z|$ & {$[95 \%$ Conf. } & Interval] \\
\hline \multicolumn{7}{|l|}{ hazard } \\
\hline Injunemp & 1.667744 & .0115095 & 144.90 & 0.000 & 1.645186 & 1.690302 \\
\hline Injunemp2 & -.6094896 & .0036285 & -167.97 & 0.000 & -.6166014 & -.6023779 \\
\hline month12 & .2509031 & .0189203 & 13.26 & 0.000 & .2138199 & .2879862 \\
\hline month18 & .3500861 & .0319891 & 10.94 & 0.000 & .2873887 & .4127836 \\
\hline month24 & .8402277 & .0405105 & 20.74 & 0.000 & .7608285 & .9196268 \\
\hline $\mathrm{ub}$ & -1.13203 & .0224224 & -50.49 & 0.000 & -1.175977 & -1.088083 \\
\hline ubxlnjunemp & .3957091 & .0151461 & 26.13 & 0.000 & .3660233 & .4253949 \\
\hline female & -.2224591 & .0087931 & -25.30 & 0.000 & -.2396933 & -.2052248 \\
\hline age16tv & .1636392 & .0030138 & 54.30 & 0.000 & .1577322 & .1695462 \\
\hline age16tv2 & -.008975 & .0002028 & -44.25 & 0.000 & -.0093725 & -.0085775 \\
\hline educcompul1 & .0617471 & .0115434 & 5.35 & 0.000 & .0391224 & .0843717 \\
\hline educcompul2 & .1907854 & .0088367 & 21.59 & 0.000 & .1734658 & .2081049 \\
\hline inmigra & .0416093 & .0130047 & 3.20 & 0.001 & .0161205 & .0670981 \\
\hline unrate & -.0663027 & .0007754 & -85.51 & 0.000 & -.0678225 & -.064783 \\
\hline andal & .3799678 & .0128413 & 29.59 & 0.000 & .3547993 & .4051363 \\
\hline aragon & -.2044564 & .0254538 & -8.03 & 0.000 & -.254345 & -.1545679 \\
\hline astur & -.2250878 & .0304658 & -7.39 & 0.000 & -.2847996 & -.165376 \\
\hline balear & -.0011708 & .0222276 & -0.05 & 0.958 & -.0447362 & .0423945 \\
\hline canar & .0881472 & .0194367 & 4.54 & 0.000 & .0500519 & .1262425 \\
\hline cantab & -.1760296 & .0354943 & -4.96 & 0.000 & -.2455971 & -.1064621 \\
\hline castman & -.0070246 & .0178225 & -0.39 & 0.693 & -.0419561 & .0279069 \\
\hline castleon & -.0212195 & .0199477 & -1.06 & 0.287 & -.0603162 & .0178773 \\
\hline valenc & .1237376 & .0136243 & 9.08 & 0.000 & .0970345 & .1504407 \\
\hline extrem & .268271 & .0286872 & 9.35 & 0.000 & .2120451 & .3244969 \\
\hline galic & -.0809457 & .017349 & -4.67 & 0.000 & -.1149491 & -.0469424 \\
\hline murcia & .0693928 & .0223672 & 3.10 & 0.002 & .0255539 & .1132317 \\
\hline navarr & -.2946294 & .0440801 & -6.68 & 0.000 & -.3810248 & -.208234 \\
\hline vasco & -.2276128 & .0250431 & -9.09 & 0.000 & -.2766964 & -.1785292 \\
\hline rioja & -.1576675 & .0483877 & -3.26 & 0.001 & -.2525057 & -.0628293 \\
\hline _cons & -2.903889 & .0173715 & -167.16 & 0.000 & -2.937937 & -2.869842 \\
\hline \multicolumn{7}{|l|}{$\mathrm{m} 2$} \\
\hline _cons & 1.037042 & .0079216 & 130.91 & 0.000 & 1.021516 & 1.052568 \\
\hline \multicolumn{7}{|l|}{ logitp2 } \\
\hline _cons & -.5535301 & .0306487 & -18.06 & 0.000 & -.6136004 & -.4934599 \\
\hline Prob. Type 1 & .6349542 & .007104 & 89.38 & 0.000 & .6209212 & .6487617 \\
\hline Prob. Type 2 & .3650458 & .007104 & 51.39 & 0.000 & .3512383 & .3790788 \\
\hline
\end{tabular}

Note: $\mathrm{m} 1=0$

. display "Finished at \$S_TIME"

Finished at $20: 28: 33$ 


\section{Estimation output of fitting a multispell three mass-points model using hshaz2}

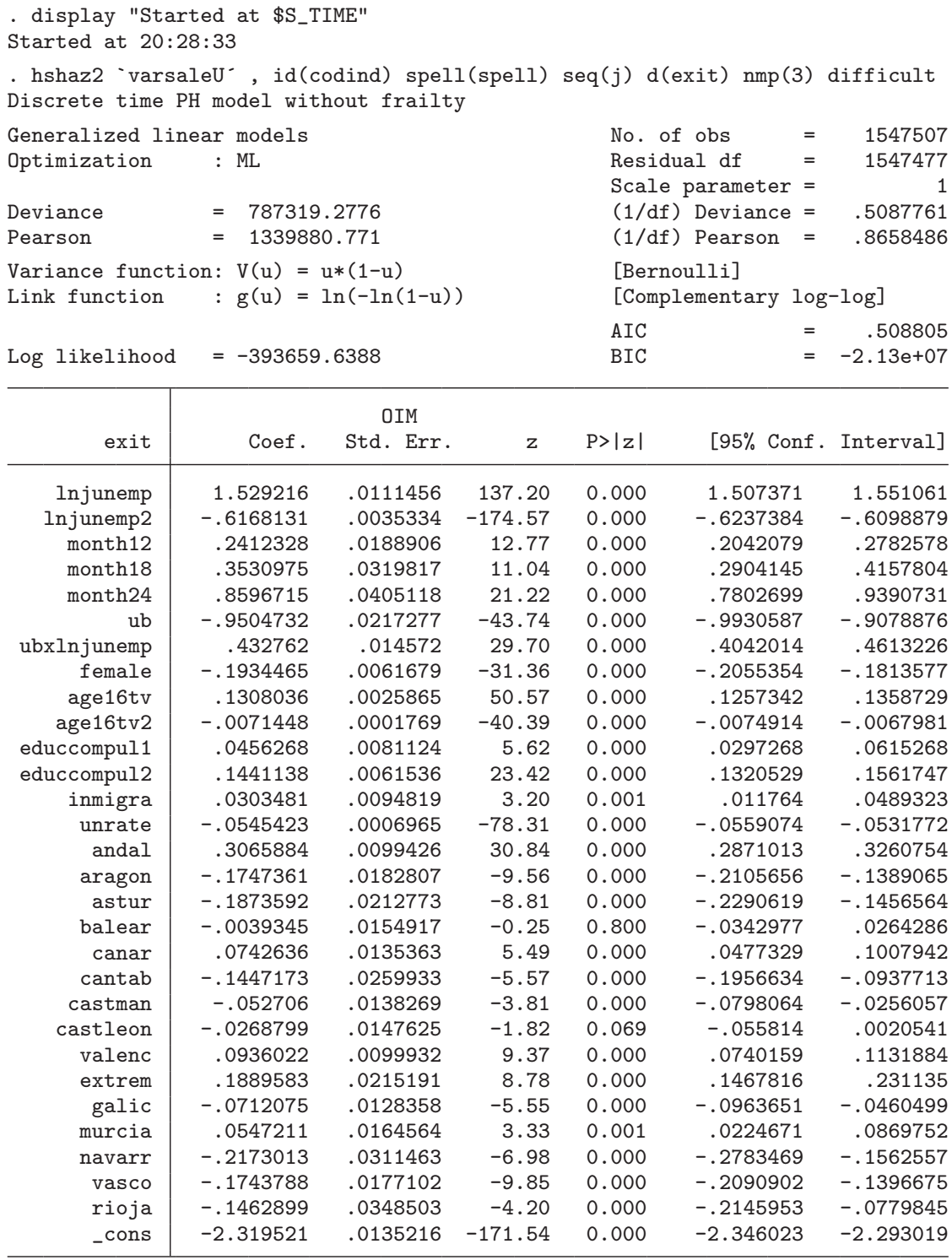

Iteration 0: $\log$ likelihood $=-391623.26$ (not concave)

Iteration 1: log likelihood $=-389180.98$

Iteration 2: log likelihood $=-389080.88$

Iteration 3: $\quad \log$ likelihood $=-388981.61$

Iteration 4: $\quad \log$ likelihood $=-388976.12$

Iteration 5: log likelihood $=-388976.1$ 
Log likelihood $=-388976.1$

\begin{tabular}{|c|c|c|c|c|c|c|}
\hline exit & Coef. & Std. Err. & $z$ & $P>|z|$ & {$[95 \%$ Conf } & Interval] \\
\hline \multicolumn{7}{|l|}{ hazard } \\
\hline Injunemp & 1.712728 & .0117502 & 145.76 & 0.000 & 1.689698 & 1.735758 \\
\hline Injunemp2 & -.6112412 & .0036843 & -165.91 & 0.000 & -.6184622 & -.6040201 \\
\hline month 12 & .2474808 & .0189257 & 13.08 & 0.000 & .2103871 & .2845746 \\
\hline month18 & .349069 & .0319958 & 10.91 & 0.000 & .2863583 & .4117797 \\
\hline month24 & .8442376 & .0405235 & 20.83 & 0.000 & .764813 & .9236622 \\
\hline $\mathrm{ub}$ & -1.202758 & .0228459 & -52.65 & 0.000 & -1.247535 & -1.15798 \\
\hline ubxlnjunemp & .4153211 & .0153594 & 27.04 & 0.000 & .3852173 & .4454249 \\
\hline female & -.2483482 & .0096691 & -25.68 & 0.000 & -.2672994 & -.229397 \\
\hline age16tv & .1742109 & .0031385 & 55.51 & 0.000 & .1680596 & .1803622 \\
\hline age16tv2 & -.0096088 & .0002126 & -45.20 & 0.000 & -.0100255 & -.0091921 \\
\hline educcompul1 & .0692114 & .0127609 & 5.42 & 0.000 & .0442004 & .0942224 \\
\hline educcompul2 & .1954493 & .009653 & 20.25 & 0.000 & .1765298 & .2143688 \\
\hline inmigra & .0173987 & .0141252 & 1.23 & 0.218 & -.010286 & .0450835 \\
\hline unrate & -.0692682 & .0007989 & -86.70 & 0.000 & -.070834 & -.0677024 \\
\hline andal & .3859115 & .0138425 & 27.88 & 0.000 & .3587807 & .4130423 \\
\hline aragon & -.2163093 & .0270087 & -8.01 & 0.000 & -.2692454 & -.1633733 \\
\hline astur & -.2086945 & .0305259 & -6.84 & 0.000 & -.2685243 & -.1488648 \\
\hline balear & -.0051452 & .023331 & -0.22 & 0.825 & -.050873 & .0405827 \\
\hline canar & .0938902 & .0203456 & 4.61 & 0.000 & .0540136 & .1337669 \\
\hline cantab & -.1922947 & .0393454 & -4.89 & 0.000 & -.2694104 & -.1151791 \\
\hline castman & -.0143631 & .0195106 & -0.74 & 0.462 & -.0526032 & .0238769 \\
\hline castleon & -.0274502 & .0214405 & -1.28 & 0.200 & -.0694728 & .0145724 \\
\hline valenc & .129262 & .0150897 & 8.57 & 0.000 & .0996867 & .1588373 \\
\hline extrem & .2572255 & .0300622 & 8.56 & 0.000 & .1983047 & .3161464 \\
\hline galic & -.0958032 & .0194259 & -4.93 & 0.000 & -.1338771 & -.0577292 \\
\hline murcia & .0681206 & .0245183 & 2.78 & 0.005 & .0200656 & .1161756 \\
\hline navarr & -.2795309 & .04251 & -6.58 & 0.000 & -.3628491 & -.1962128 \\
\hline vasco & -.2360774 & .0272906 & -8.65 & 0.000 & -.2895659 & -.1825888 \\
\hline rioja & -.1887588 & .0481213 & -3.92 & 0.000 & -.2830748 & -.0944428 \\
\hline _cons & -2.288511 & .0224326 & -102.02 & 0.000 & -2.332478 & -2.244544 \\
\hline \multicolumn{7}{|l|}{$\mathrm{m} 2$} \\
\hline _cons & .984602 & .0177674 & 55.42 & 0.000 & .9497785 & 1.019425 \\
\hline \multicolumn{7}{|l|}{$\mathrm{m} 3$} \\
\hline _cons & -.8866318 & .0105559 & -83.99 & 0.000 & -.9073211 & -.8659425 \\
\hline \multicolumn{7}{|l|}{ logitp2 } \\
\hline _cons & -1.542246 & .0543574 & -28.37 & 0.000 & -1.648784 & -1.435707 \\
\hline \multicolumn{7}{|l|}{ logitp3 } \\
\hline _cons & -.0923742 & .0484258 & -1.91 & 0.056 & -.1872871 & .0025386 \\
\hline Prob. Type 1 & .4704412 & .0098954 & 47.54 & 0.000 & .4511009 & .4898707 \\
\hline Prob. Type 2 & .1006275 & .005503 & 18.29 & 0.000 & .0903435 & .1119381 \\
\hline Prob. Type 3 & .4289313 & .0122819 & 34.92 & 0.000 & .4050452 & .4531531 \\
\hline
\end{tabular}

Note: $\mathrm{m} 1=0$

. display "Finished at \$S_TIME"

Finished at 20:30:50 